\title{
Analysis on Dynamic System of the Cultural and Creative Tourism Product Development
}

\author{
Chunyan Wang \\ College of Business Administration, Jilin Engineering Normal University, Changchun, China \\ wangchunyan9010@163.com
}

Keywords: The cultural and creative tourism product; Main forms; Dynamic system; Development

\begin{abstract}
The development of cultural and creative tourism product is influenced by the five aspects of the profit, creativity, competition, government and opportunity. The capital, talent, technology and intellectual property constitute its supporting elements, and the financing difficulties and intellectual property issues become the resistance factors of developing the cultural and creative products. On the basis on analyzing the driving aspects, supporting elements and resistance factors, we construct the dynamic system of the cultural and creative tourism product development.
\end{abstract}

\section{Introduction}

As one of the most influential economists of the 20th century, Joseph Alois Schumpeter has focused on the importance of creativity in the development of economy, but at that time he stressed that the focus is on the innovation of technology and management [1]. At the end of 20th century, the United Kingdom set up the creative industry group, and vigorously developed the creative economy. The status of the creative has become increasingly prominent in the economic development. At this stage, the creativity is closely linked with culture and art, leisure and entertainment [2]. With the spread of the creative economy concept, creativity has gradually integrated into the development of cultural tourism, and promoted cultural tourism to show the creative trend, which promoted the integration of cultural tourism and creative industry, and it also provided the inspiration for developing experiential tourism products, which directly promoted the production of cultural and creative tourism products.

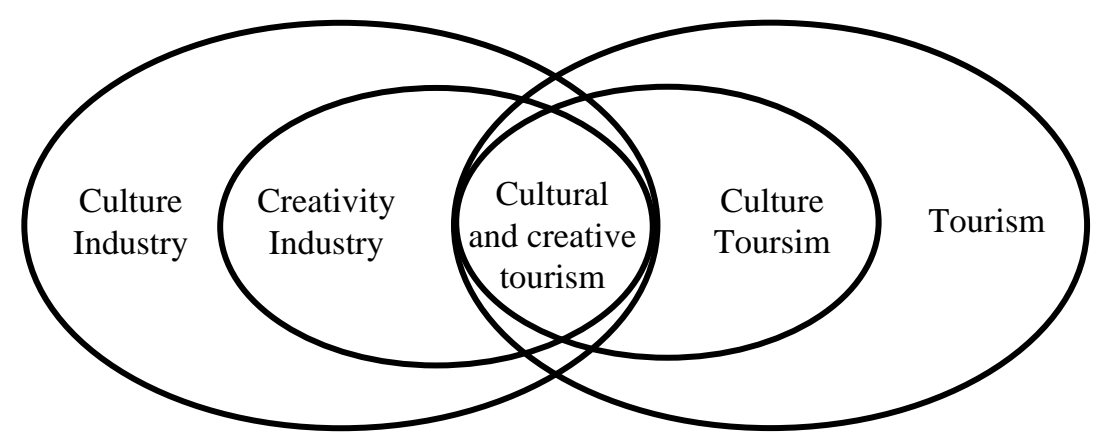

Figure 1. Subordinate relationship of cultural and creative tourism

The creative elements are put into the tourism industry, which can convert these things that are not tourism resources into tourist attractions [3]. The cultural and creative tourism is produced by the combination of creative industry and cultural tourism in the tourism industry, which change the original tourism products by creative ideas, so as to attract tourists (Fig. 1). The basis of cultural and creative tourism product is cultural resource, and innovation is its soul, that is the result of combining cultural creativity with six elements of tourism.

\section{Main Forms of Cultural and Creative Tourism Products}

Different from the traditional tourism products, cultural and creative tourism products are more inclined to performance, activity, visual impact, individual experience and other interactive elements, 
which emphasizes the cultural attributes, originality, novelty and artistic, and has a dependency on creativity with strong participation and experience, its specific forms of product are in Table 1:

Performances. This kind of cultural and creative tourism product mainly refers to the integration of creative elements, such as performing arts and music creation, with tourism activities [4]. Performing arts can become tourism resources for attracting tourists through the creative process, such as South Korea's "Nanta" show, the Moulin Rouge in France, Songcheng Eternal Love and Shaolin Zen Music Ritual in China and so on. In China, relying on the performing arts, the "Impression Liu Sanjie" show in the real landscape of Guilin, which is create the "Impression Series" in tourism performances. Than "impression Da Hong Pao", "Impression Westlake", "Impression Lijiang" and other works, they emerge in an endless stream. That greatly enriched the tourist's travel experience, and made the tourists deeply appreciate the charm of the local culture.

Table 1 Categories and main forms of cultural and creative tourism products

\begin{tabular}{ll}
\hline Categories & Main forms \\
\hline Performances & Song and dance performances, drama, etc. \\
Media art & film shooting base, movie theme park, etc. \\
Visual arts & $\begin{array}{l}\text { Art museum, sculpture park, cultural theme park, individual works exhibition, } \\
\text { characteristic museum, etc. }\end{array}$ \\
Festivals and events & Music Festival, Film Festival, Drama Festival, Fashion Festival, etc. \\
Creative park & IT park, animation theme park, cultural and creative park, etc. \\
Manual arts & Manual workshop, non-material cultural heritage display, etc. \\
\hline
\end{tabular}

Media Arts. With the help of the publishing, film, television, advertising, radio and other media from creative industry, it evolves this new type of tourism product, which is created by using the media resources. The representative products including the film shooting base opening to visitors and the movie theme park by using the film technology, such as Hengdian World Studios, Disneyland, Movie Wonderland and so on.

Visual Arts. It is a sort of tourism product based on the sensory stimulation of visual arts to attract tourists, which relies on the design and visual arts in creative industry, including art galleries, sculpture parks, cultural theme parks, individual works exhibition, etc.. In addition, it also includes virtual scenic spots, just like Mogao Grottoes Visitor Center which is officially opened in August 2014. By using the 3D technology, Mogao Grottoes murals exhibition can be a global tour, which breaks through the space limitations of tourism product.

Festivals and Events. It makes the festivals and events to create tourism resources by using creative ideas, and the cultural creativity will attract tourists. The mature products are mainly the World Expo, music festivals, drama festivals, film festivals and so on. The more representative ones including the Venice Film Festival, Cannes Film Festival, the Glastonbury Festival and Reading and Leeds Festival in UK, Coachella Valley Music and Arts Festival in California, Summer Sonic Festival in Japan, etc. [5]. These festivals and events can attract a large number of tourists to participating every year.

Creative Park. It takes the creative park or heritage sites with the creative transformation as the main attraction. This kind of tourism product has the function of education, entertainment and leisure and so on, that including IT park and animation theme park which both rely on the creative industry, such as Hello Kitty Park in Japan, as well as the creative park which has become a tourist destination by creative transformation, just like DAD-Dashanzi Art District in Beijing, and including the industrial heritage tourist destination that the Iron Bridge Gorge is the very representative.

Manual Arts. This kind of cultural and creative tourism product takes the craftsmanship or other non-material cultural carrier as the demonstration content. Tourists get the value of tourism product by watching, participating, learning and other ways, which is the main form of many non-material cultural heritage products. The performance of handicraft production and sales is a typical representative in Poble Espanyol de Barcelona, which was built for the World Expo in 1929. 


\section{Analysis on Dynamic System of the Cultural and Creative Tourism Product}

The dynamic system of the cultural and creative tourism product development can have an effect of driving, mainly driven by the five aspects of driving force: profit, creative, competition, government and opportunities. Capital, talent, technology and intellectual property protection are the supporting elements of the dynamic system to provide the support for implementing product development. Drive systems and support systems constitute the main driving force for the development of cultural and creative tourism products [6]. And because of financing difficulties, lack of intellectual property protection and other issues, these factors will affect the progress and sustainability of product development, formed the resistance system, and caused interference on the product development. Two aspects of pull and resistance determine the implementation of cultural and creative tourism product development (Fig. 2).

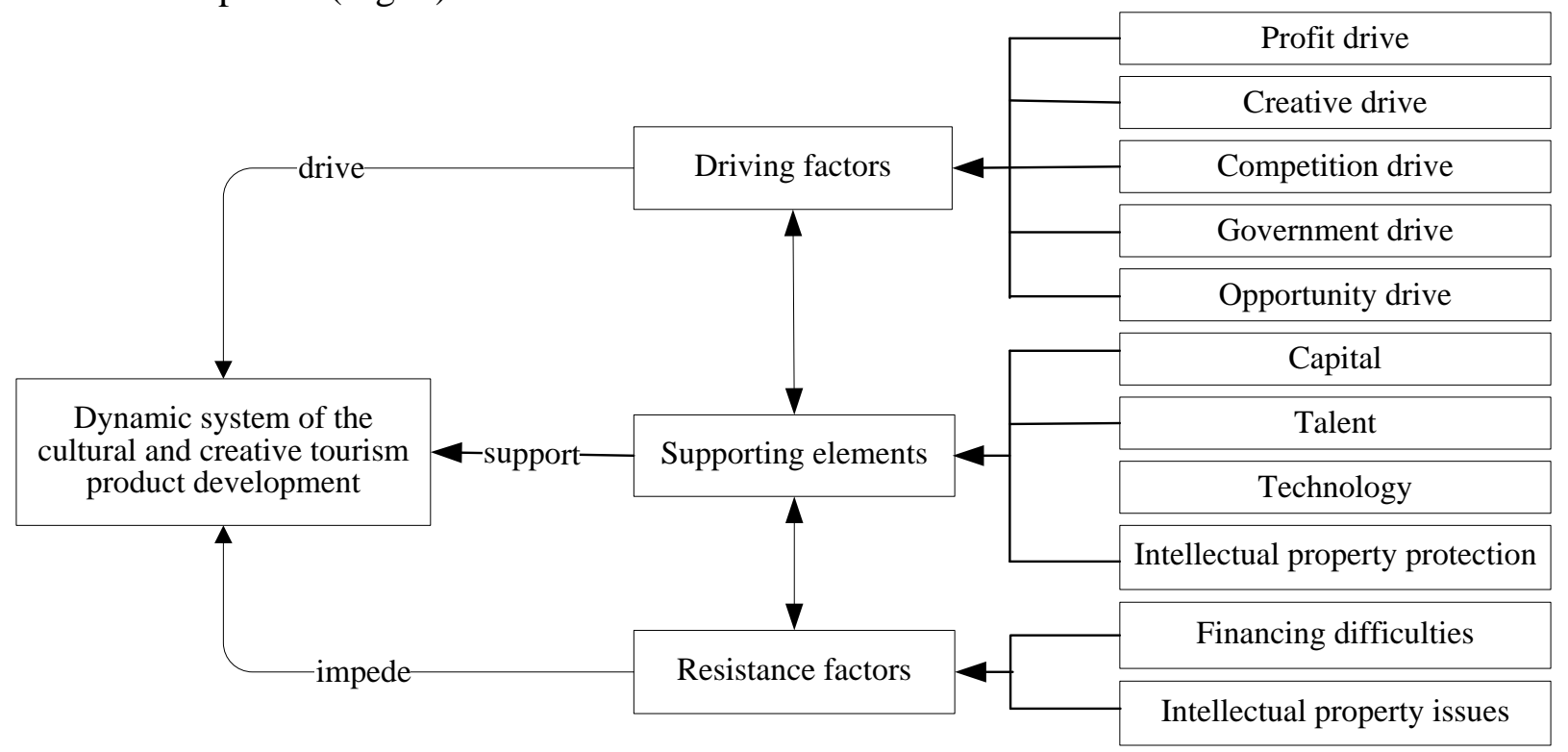

Figure 2. Dynamic system of the cultural and creative tourism product development

Driving Factors. Some driving factors can influence on the development of cultural and creative tourism product, such as profit, creation, competition, government and opportunity and so on. According to the "Push-Pull Model", the diversification of tourist demand will have a great impetus to the development of cultural and creative tourism. A variety of tourism service demands make consumers to have a travel motivation, and thus promote the production of demand [7]. The tourist demand for cultural and creative tourism product has been present. The cultural and creative tourism products are in short supply. In addition to obtain the normal operating profits, the cultural and creative tourism producers (the creative department in travel agency, intermediary in creative industry, etc.) can fetch the excess profits due to insufficient supply of product. Thus, the producers want to obtain excess profits, so the profit-driven pull is formed. The intellectual elements of creativity are provided by the tourism enterprises and creative sectors. In the process of developing products, the artists and planning workers in the creative sectors with tourism attractions, travel agencies, hotels in the tourism produce and provide the cultural creative tourism products together. In the cultural and creative tourism industry, the creative sectors put the creative thinking, intellectual technology and ideas into the products, and to reorganize and integrate the original static tourism elements, to create the cultural and creative tourism products, providing creative tourism services. With the continuous improvement of people's living standards, the tastes and demands of tourists are becoming higher increasingly. In order to win more customers, the competition among tourism enterprises is also growing. For achieving a dominant position in the competition, the tourism enterprises have to search for and select the differentiated tourism products. In addition to a very high level of experience and participation, the cultural and creative tourism products also have a high level of intelligence. When the fixed cost remains unchanged, it can reduce the variable costs by using the intelligence factors, to 
decline the average cost of products. Therefore, in order to win in the competition, many tourism enterprises are willing to choose a creative supplier to provide innovative tourism products. Although the government belongs to the external power, it has a great impact on each element of the dynamic system model. For having cross-regional and comprehensive characteristics in the tourism production, the government needs to carry out effective coordination to each link of the tourism product production [8]. The government can build a platform for the development of the creative industry and tourism industry, guide the transformation of tourism industry to the knowledge-intensive by using the policy-oriented, support the construction of Cultural Industry Park, to encourage the industrial agglomeration and development of the cultural and creative industry, formulate relevant laws and regulations to protect the intellectual property of the cultural and creative tourism products. All the above measures have a positive effect on promoting and facilitating the development of cultural and creative tourism products. Opportunity-driven has diversified characteristics. On the one hand, the development of creative economy offers a favorable opportunity for the growth and development of cultural and creative tourism industry. Due to the cooperation between creative industry and tourism industry, it provides new approaches and new ideas for the development of cultural and creative tourism products. On the other hand, the emergence of creative talents and rapid development of information network technology have created favorable conditions for the development of cultural and creative tourism products.

Supporting Elements. The capital, talent, technology and intellectual property protection can support the development of cultural and creative tourism product. Compared with the traditional tourism products, the cultural and creative tourism products need more investment and R\&D funds. Chinese Tourism "Impression" series of landscape performances as an example, the basic development cost up to several billion yuan. So the capital is an important factor for the sustainable development of cultural and creative tourism products. In the era of creative economy, knowledge and creativity have become the main source of wealth creation and economic growth, and talents become the main factor of production. An industry's competitive advantage comes from the ability to quickly mobilize talent and resources to transform the ideas into a commercial product. Creativity emphasizes the individual participation and wisdom. In the process of developing the cultural and creative tourism product, the talent is the crucial element. When the creativity is transformed into the products, the producer needs to have high-tech means. Due to the difference with other tourism products, most of the cultural and creative tourism products need advanced technology as an auxiliary tool. A movie theme park, for example, is a new type of tourism product which is the combination of technologies about light, sound and electricity. So the related technology is an essential supporting element in the development of cultural and creative tourism product. Cultural and creative tourism product is a new kind of tourism product with intellectual property rights as the core values, so it needs to be protected its innovations by intellectual property law. Creativity can create wealth under intellectual property protection. The cultural and creative tourism products can be better developed in some areas where have well-established the system of intellectual property protection. For the cultural and creative tourism products, their originality is often reflected in a kind of design, thinking or innovation [9]. If their intellectual property rights can not be protected effectively, the inputs of original staff which create one new product will be difficult to recover or even in vain. It will seriously hamper the sustainability of product development over time. Thus, intellectual property protection is a key factor to the survival and development of cultural and creative tourism product.

Resistance Factors. Financing difficulties and intellectual property issues will hinder the process of cultural and creative tourism product development. The core value of cultural and creative tourism product is copyright, that covers a high proportion on intangible assets, but the value of intangible assets assessment is difficult and the its market value has a lot of uncertainty, which leads to investment with a higher risk. The scale of enterprise is small in the cultural and creative industry and tourism industry. These enterprises are unlikely to be significant capital investment, and can not afford a long cycle of capital turnover. Coupled with the lack of internal financing capacity and the poor of external financing channels, these enterprises are facing the prominent difficulties of 
financing. It is extremely unfavorable to the orderly market competition that a large number of intellectual property infringements happen in the cultural and creative tourism industry. Due to the lack of legal protections and legal consciousness, some cultural and creative tourism products are imitated and copied by peers in a short period of time, but these tourism enterprises which design and develop these products may put in much time and money. The plagiarism not only harms the interests of the product development enterprises, but also severely hurts the enthusiasm of them to innovate.

\section{Conclusion}

The development of cultural and creative tourism product has been done and has been successful in the tourism developed areas of the world [10]. Previous cultural and creative tourism products are more focused on the surface of scene and performance practice, but in the depth of communication and interaction with tourists, the participation and experience of product still need to be improved. Some creative activities also lake the design which can touch the soul and cause inner resonance of tourist, but still stay in the low level of creative display. There are many difficulties and problems to be solved in financing and intellectual property protection of cultural and creative tourism product development. Deepen development requires the full participation and effort of government, tourism enterprise, creative enterprises, etc. This paper only discusses on the dynamic factors of the development of cultural and creative tourism products, and constructs the dynamic system of cultural tourism product development. But it also needs to be further studied in the aspects of tourism product design, industrial extension and management and so on.

\section{Acknowledgements}

This work was financially supported by Social Science Foundation of Jilin Provincial Education Department ([2014] No.427) and the Research and Development Project of Jilin Engineering Normal University (X2015039).

\section{References}

[1] N. Leiper: Annals of Tourism Research, Vol. 17 (1990) No.3, p.367-384.

[2] G. Richards and C. Raymond: ATLAS News, Vol. 23 (2000), p.16-20.

[3] A. Catalani: World Leisure Journal, Vol. 55 (2013) No.3, p.252-263.

[4] A. Essica, P. Rhonda and H. Sung: Tourism Culture and Communication, Vol. 12 (2012) No.1, p.5-18.

[5] Information on https://en.wikipedia.org/wiki/Film_festival

[6] L.Y. Qian: A Study of the Development of Creative Tourism Industry based on Dynamic mechanism (MS., Xiamen University, China 2009), p.30-35.

[7] Z.F. Wang and X.L. Huang: Journals of Shandong Social Sciences, Vol. 181 (2010) No.9, p.118-122.

[8] H.Y. Song: Journal of Inner Mongolia University for Nationalities (Social Sciences), Vol. 41 (2015) No.3, p.77-80.

[9] G. Richards: Current Issues in Tourism, Vol. 17 (2014) No.2, p.119-144.

[10] A. Djukic and M. Vukmirovic: Techincs Technologies Education Management-TTEM, Vol. 7 (2012) No.4, p.1768-1778. 